\title{
A Simple Gaze Tacker for Computer Operation by the Disabled in Education
}

\section{Um Rastreador Visual Simples para o funcionamento do Computador por Pessoas com Deficiência na Educação}

\begin{abstract}
A compact gaze tracker was developed which consists of a head band and electrodes which process the ElectroOculo-Gram (EOG) reflecting the patient's eye movements. We have confirmed that the processed EOG signal correlates well with gaze angle, and we show that the instrument we designed enables a child to move a target on a screen up to 40 degrees left-right from central sight. To achieve this, a signal processing circuit was designed and placed on a head band to minimize noise. Further processing is based on the identification of saccadic eye movements and on the educated calculation of the estimated gaze angle as a result of angle change in both directions. A 75\% success rate was achieved to detect transitions of eye positions in $5^{\circ}$ steps from $+40^{\circ}$ to $-40^{\circ}$. First tests by normal children suggest that the device may prove useful for communication by the disabled (e.g. patients with no control on hand movements). In such cases, extensive personal training will tap on neurological plasticity to achieve the required performance level for computer mouse command of educational games and for interactive applications in general.
\end{abstract}

Keywords: Assistive technology. Gaze-tracker. Education. Disability.

Resumo: Um rastreador visual compacto que foi desenvolvido consiste numa faixa para a cabeça com eletrodos que processam o Electro-Oculo-Gram (EOG), acompanhando o movimento do olhar do paciente. Confirmamos que o sinal processado pelo EOG correlaciona-se muito bem com o ângulo do olhar, e nos mostra que o instrumento projetado possibilita a criança mover o alvo na tela de 40 o esquerda-direita da vista central. Para isso, um circuito de processamento de sinal foi projetado e colocado em uma faixa de cabeça para minimizar ruídos. O processamento adicional foi baseado na identificação dos movimentos oculares e o cálculo estimado do ângulo da faixa resultaram na mudança do ângulo em ambas as direções. Uma taxa de $75 \%$ de sucesso foi alcançada na detecção das posições do olho numa escala de 5 은 desde $+40 \circ$ até $-40 \%$. Os primeiros testes em crianças sem deficiência indicam que o dispositivo pode ser viável para a comunicação de pessoas com deficiência (ex. sujeitos que não tem controle dos movimentos das mãos). Nesses casos, o treinamento extensivo de profissionais poderá alcançar a plasticidade neurológica requerida para comandar o mouse do computador dos jogos educacionais e aplicações interativas em geral.

Palavras-chave: Tecnologia Assistiva. Gaze Tracker. Educação. Deficiência.

SIMINI, Franco. et al. A Simple Gaze Tracker for Computer Operation by the Disabled in Education. I nformática na Educação: teoria e prática, Porto Alegre, v.15, n.2, p. 17-25, jul./dez. 2012.
Franco Simini

Universidad de la Republica

Andres Touya

Universidad de la Republica

Agustin Senatore

Universidad de la Republica

Jose Pereira

Universidad de la Republica

Laura De Castellet

NeuroPaediatric Rehabilitation Professor and Medical Director of Fundación TELETÓN

\section{Introduction}

$S$ everal medical conditions in paediatric rehabilitation include the problem of enabling the child to develop an alternative way of commanding a computer, due to a lack of hand mobility and control. A way to circumvent this condition is to consider eye movement to let the patient interact with compu- 
ter devices with which one normally interacts with hands. The movement of the eyes is well under control and has been monitored in simple life situations, a fact which suggests to use a gaze tracker as a man/machine interface to operate educational software and other interactive applications.

Eye movement research is an established field of work for physiologists and developers of biomedical instrumentation, with a growing share being taken by signal and image processing (PEREIRA; SENATORE; TOUYA, 2011, JIN; LEE; HONG, 2010). Such areas as visual perception, reading technique determination, instrument panel layout design and driving analysis have all benefited from eye movement recordings. Eye tracking has been implemented using a variety of technologies, ranging from a small coil affixed to the eye ball (using electromagnetic (EM) induction) to optic devices (using cameras to record sequences of images of the iris) and complete image processing of the head of the person (ENDERLE, 2006). Another technique for eye tracking mostly used in clinical settings processes the electrical signal detected on the skin by the eyes: the electrooculogram EOG. Infrared devices and webcams are used to obtain either simplified reflection of light or extensive video recordings to be processed.

Discarding all cumbersome and invasive techniques such as the eye-ball-affixed coil, cameras and EOG techniques both appear to be suitable for disabled children to train themselves in educational man/machine interaction based on gaze. Gaze direction has been tracked in every day life conditions - sometimes called ecological - by such devices as a webcam and associated gear mounted on a cap or on spectacles (SCHI AVONE; GUGLIEL-
MELLI; KELLER et al., 2010). The published methods enable researchers to study the visual experience from the point of view of the child patient under rehabilitation ( $\mathrm{SCHIA-}$ VONE; GUGLIELMELLI; KELLER et al., 2010). Other researchers (STIEFELHAGEN, 1997) process the image of a camera mounted on the head of the child to deduce his/her field of view and thus estimate the gaze direction.

Although the linearity of the EOG with eye position has been established, little was done (ENDERLE, 2006, STIEFELHAGEN, 1997) to use it for purposes other than basic research or diagnostics. Our aim (GONZÁLEZ; GARCíA; TULLI, 2005) was to record the eye position with a device that could be worn with minimal discomfort for a long time during the day. Initially included in the development of a prosthetic eye movement to follow the position of the healthy eye (PEREIRA; SENATORE; TOUYA, 2011), we set ourselves the goal of developing a novel, portable, non invasive and lightweight eye position detector.

\section{Specifications}

The device to be developed should be portable, cause no discomfort to the bearer, be lightweight, non invasive and capable of instant determination of gaze direction. I deally located on a pair of spectacles, the output should deliver an angular position at all times. To achieve this, we first determined the position/voltage equivalence (Section III), build a practical prototype (Section V) and asked volunteers to test it by moving a target on screen with the gaze (Section VIResults). 


\section{Angle to Voltage Conversion}

The EOG reflects eye movements with varying sign and amplitude of the signal. When the eye moves sideways, the EOG voltage on that side increases. The processed EOG voltage is proportional to the angle spanned within $30^{\circ}$ from the central position. We have taken measurements of both (i) the target angle seen by normal volunteers and (ii) the filtered EOG output to verify the linearity within +/- 30 degrees and to determine the transfer function. Figure 2 shows the curve fit (3rd order polynomial) on normalized data. The linearity is thus verified and the region from $30^{\circ}$ to $45^{\circ}$, which is not very comfortable, can be represented by a single extreme value (PEREIRA; SENATORE; TOUYA, 2011).

The gaze tracker, based on the results of Figure 1, performs an angle to voltage conversion. A fragment of conversion is shown in Figure 2. Every time there is a saccadic movement, the heavily filtered EOG exhibits a pulse. These pulses are detected, measured in real time and the new eye position is thus calculated and shown as a square wave (Figure 2).
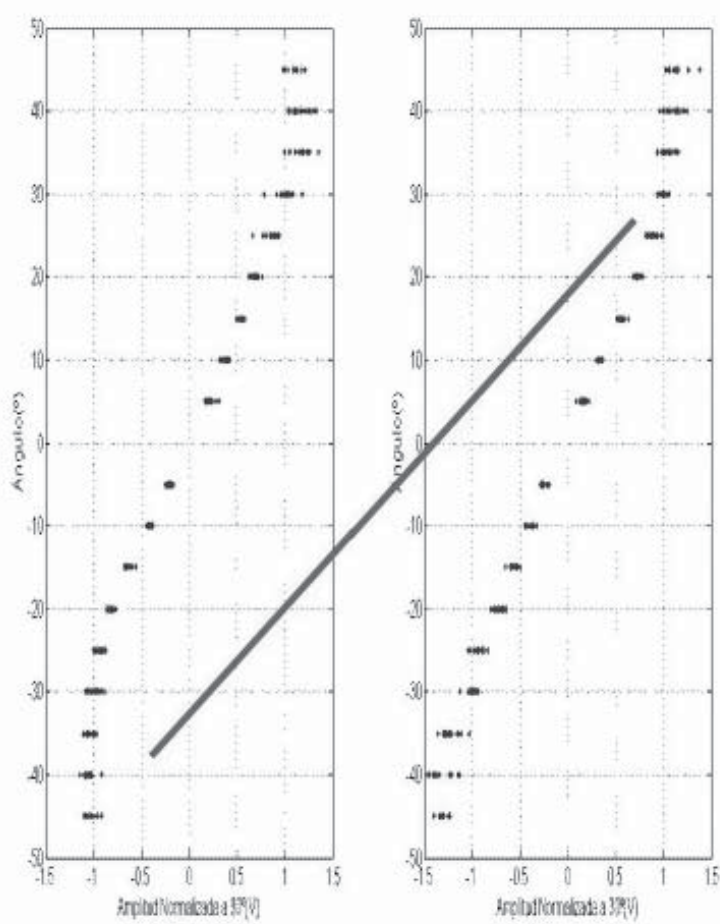

FIGURE 1 - EOG voltage and eye angle. Normalized EOG voltage on the horizontal axis and eye angle in the vertical axis. Note that within $30^{\circ}$ the correspondence can be assumed to be linear, with deviations for larger angles: as the angle increases beyond $30^{\circ}$, EOG fails to follow linearly.

SOURCE: Figure adapted from Pereira, Senatore, Touya et al. (2011).

The determination of eye movements was tested in order to evaluate the accuracy of the gaze tracker. Not all EOG signals look as noise-free as the fragment shown in Figure 2 and sometimes the available information is not enough to report the true eye position. Following a protocol of target tracking by volunteers, the output of was compared to the real eye position, with data described in the RESULTS section. 


\section{Gaze Tracker Head Band and Arm Circuit}

The design of a gaze tracker based on EOG allows to add the least possible discomfort to the person using. Unlike cameras mounted on glasses or heavy gear monted on the head, our gaze tracker was conveniently included in a head band, slightly elactic and with Velcro fastening, as shown in Figure 3. The head band includes metal electrodes to be affixed onto the nasal septum and which gently press on the temples. As expected, the skin must be prepared in order to optimize the signal picked up.

The pre processing circuit is located in a slim plastic box glued onto the head band so as to shorten as much as possible the noise which is collected by connections of low amplitude biological signals in electrically noisy environments.

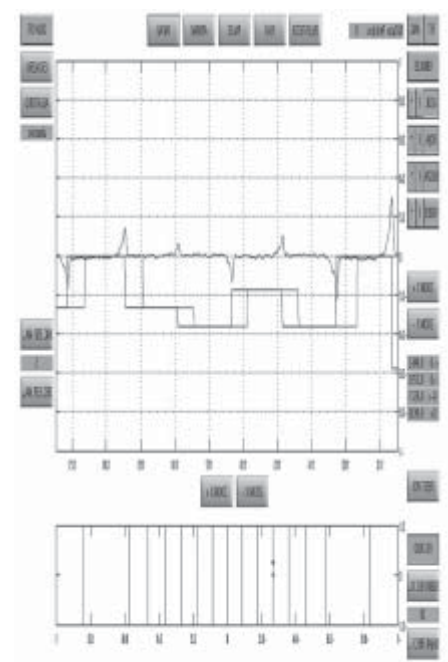

FIGURE 2 - Peaks represent EOG processing as saccades are detected right (positive voltage) or left (negative voltage) of centre sight. Square waves are the target submitted to the subject and the gaze direction reconstructed by the gaze tracker. Vertical dotted lines are separated one second from each other. Vertical values are arbitrary amplitude units, derived from the EOG processing. There is a $350 \mathrm{~ms}$ delay from the target movement to the eye response.

SOURCE: Figure adapted from Simini, Touya, Senatore et al. (2011).

Coming out of the head band there is a cable which conveys the preprocessed EOG signal, ready to be turned into a digital angle of sight by a circuit locted in a box, which can be either worn at the belt or tied on the outside of the arm as shown in Figure 4.

The position of the eye is determined and the sequence of positions stored in a local memory of the arm box (Figure 4) of the gaze tracker. This data position may be conveniently transposed to the computer where a mouse driver or similar software structure can handle the position of a cursor or point, implementing a mouse, for instance.

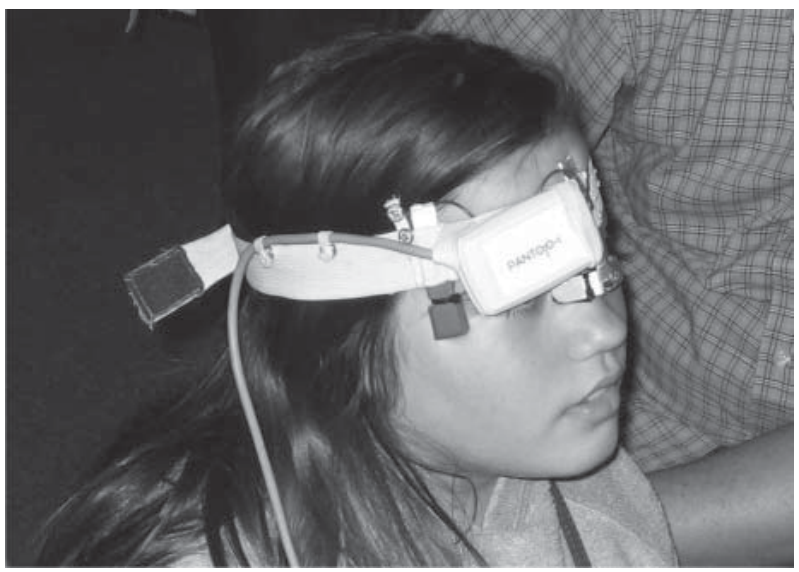

FIGURE 3 - Head-band of the gaze tracker. Note the amplifier circuit is located only a few centimetres away from the electrodes. The central electrode is applied on the nasal septum and the two lateral electrodes on the temples. The cable conveys the pre processed EOG to am arm circuit with a wireless link to a computer.

SOURCE: Our authoring 


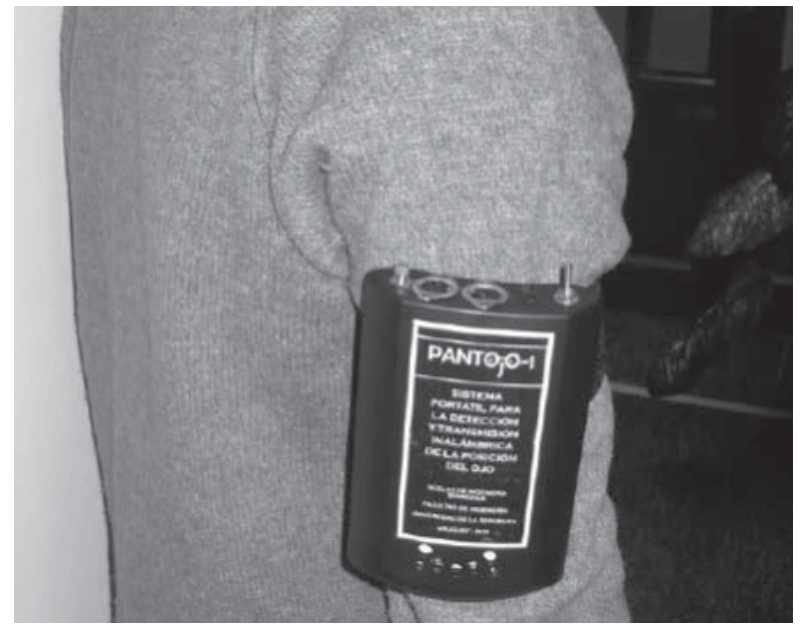

FIGURE 4 - Arm circuit of the gaze tracker. The EOG signal processing is located in this box, as well as the wireless circuitery to communicate the gaze position to the mouse driver installed in the Computer.

SOURCE: Our authoring

\section{Building Blocks}

The gaze tracker consists of the following blocks:

- electrodes on a head band

- amplification and filtering located on the very head band

- A/D and signal processing in an arm/ belt unit

- wireless link of eye position to computer.

In order to reduce noise, amplification was put very close to the original EOG signal. We therefore located it $5 \mathrm{~cm}$ away from the electrodes (Figure 3). The electrodes and the amplifier are located on an elastic head-band secured with velcro at the nucha (Figure 3). The EOG signal is taken differentially from an electrode on the nasal septum and one on the temple. The other temple electrode is used as the reference electrode. An overall amplification of $66 \mathrm{~dB}$ with a bandpass of $1 \mathrm{~Hz}-20 \mathrm{~Hz}$ (resulting in a $7 \mathrm{~dB}$ attenuation at $50 \mathrm{~Hz}$ ) was implemented.

Analog to Digital (A/D) and further processing of the signal is located in a handy box to be worn at the belt or the arm (Figure 4) and includes a Microchip PIC 18F2553. The digital eye position is output with a Bluetooth KC21 element by KC wirefree Ltd.. Power supply is a set of AA batteries.

The weight of the prototype is $120 \mathrm{~g}$ (band) plus $280 \mathrm{~g}$ (belt/arm module).

\section{Results}

The performance of the gaze tracker was evaluated considering the transitions that occur between eye positions. The gaze tracker starts with a central sight position of $0^{\circ}$ and adds or substracts eye movements either left or right according to the detected saccadic movements. The position of the eye is limited to a set of angles, multiples of $10^{\circ}$. We measured the ability of the device to detect correctly the transition from a left gaze of $20^{\circ}$ to a left gaze of $10^{\circ}$, for instance, and similarly all possible - and physiological - transitions. Table 1 shows the results of 420 comparisons of the calculated eye position change with the real eye movement of three volunteers. 
TABLE 1 - Percentages of Correct Determination of Eye Position Transitions in Multiples of $10^{\circ}$

\begin{tabular}{|c|c|c|c|c|c|c|c|c|c|}
\hline \multicolumn{7}{|c|}{ Eye Position After Movement Performed by Test } \\
\hline $\begin{array}{c}\text { Initial } \\
\text { Posi- } \\
\text { tion }\end{array}$ & $-40^{\circ}$ & $-30^{\circ}$ & $-20^{\circ}$ & $-10^{\circ}$ & $0^{\circ}$ & $10^{\circ}$ & $20^{\circ}$ & $30^{\circ}$ & $40^{\circ}$ \\
\hline$-40^{\circ}$ & & & & & 95 & & & & \\
\hline$-30^{\circ}$ & 85 & & 81 & 88 & 55 & & & & \\
\hline$-20^{\circ}$ & 82 & 68 & & 69 & 82 & & & & \\
\hline$-10^{\circ}$ & & 89 & 58 & & 68 & 61 & & & \\
\hline $0^{\circ}$ & & & 85 & 80 & & 84 & 77 & & \\
\hline $10^{\circ}$ & & & & 73 & 81 & & 80 & 67 & \\
\hline $20^{\circ}$ & & & & & 74 & 78 & & 72 & 72 \\
\hline $30^{\circ}$ & & & & & 50 & 62 & 64 & & 73 \\
\hline $40^{\circ}$ & & & & & 79 & & & & \\
\hline
\end{tabular}

SOURCE: After Simini, Touya and Senatore et al. (2011)

In Table 1, rows show the initial position of the eye movement performed by the subject, movement that ends at a position given by the column heading. Figures are given in percentage of successful determination. For instance the mean success rate of movements that started at the extreme left position $(-\mathbf{4 0})$ and ended in central sight was $95 \%$. No saccades from the right side of sight to the left side (nor vice versa) have been examined, so that Table 1 only reports movements within each half plane of sight. The main diagonal is trivial as it represents no movement. We found no pattern in the table, and therefore decided the overall figure could be deduced by a general average of success rate spanning all voluntary saccades.

The overall accuracy of the gaze tracker was $76.6 \%$ of correct determination of gaze angle, with values ranging from $50 \%$ to $95 \%$ of saccadic movements (Table 1 ). The same procedure, but with a $5^{\circ}$ criteria, gives a lo- wer accuracy, with a success rate as low as $37.7 \%$ of correct determinations.

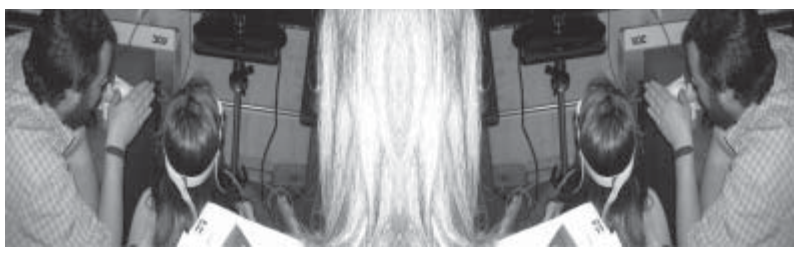

FIGURE 5 - Child receiving instructions to light one of 5 visible circles on screen by moving the eyes. This experiment has confirmed that man/machine interaction can be accomplished with the gaze tracker on head band developed.

SOURCE: Our authoring

\section{Conclusions and Discussion}

We have verified with our own data that the processed EOG amplitude of the saccades has a linear behaviour with respect to the angle subtended by the eye, within $30^{\circ}$ on either side of the central line of sight. Outside this range, a smaller EOG voltage/angle increase is found. We have developed a device which treats the EOG close enough to the skin so as to minimize noise, then processes the digital EOG detecting peaks to output information as to the eye position. This algorithm is based on stable eye positions, resulting in a state machine logic. The device detects transitions of definite eye positions or saccadic movements of single saccades. Smooth pursuit eye movements (those that take over one second to describe $40^{\circ}$ ) are not detected because it is not possible to distinguish it from a drift in electrical baseline. This limitation is nevertheless of lesser importance as the gaze tracker is used voluntarily by a subject imposing a definite and quick movement to the eyes in 
order to shift a point on the screen. When the patient will train to command a sign on screen, the volitive action will certainly be quick, resulting in a voluntary saccadic movement.

The successful determination of over $75 \%$ of transitions is obtained when the leaps are rounded to the closest $10^{\circ}$, a somewhat disappointing result, but good enough to start consistent interaction training. Such definition gives a fair confidence that at least three lateral eye positions are detected by the gaze tracker, in addition to central sight.

The estimated eye position given by our gaze tracker is therefore the result of a succession of sums and substraction of angles. Errors due to the suboptimal accuracy lead inevitably to an error which will be accumulating over time, giving a distorted position, which may be corrected by a suitable calibration of gaze angle. This issue may be tackled by assuming that the central sight is by far the most frequent one. Central sight is physiologically seek for eye comfort. To this end the statistics of the estimated eye position could be used to create an automatic calibration. This calibration may be designed to periodically correct all angles in such a way that the mode of gaze direction be assigned the value of $0^{\circ}$. After using the sight saccades to interact with the computer, the child in rehabilitation playing a game will inevitably pay attention to the centre of the screen, thus giving valuable information to the system which will assign an angle of $0^{\circ}$, irrespective of the current sum of saccades detected. By an adaptive matching of eye angle distributions with the calculated distribution, one could determine correct the calibration constant by assigning, say $40^{\circ}$ to the extremes of the present uncalibrated distributionand $0^{\circ}$ everytime the position is held for a long time, suggesting central sight.

A saccade is a very quick movement (a $10^{\circ}$ saccade can occur in $50 \mathrm{~ms}$ ) (JIN; LEE; HONG, 2010) but the signal processing of the EOG may take afew times that time - sayup to $300 \mathrm{~ms}$ - because it has to wait until the waveform of the saccade is fully processed. This delay may give the man machine interaction some delay. Given a new instrument to highlight on screen one of several objects in a row, the user can quickly learn to fix his gaze to a given point, thus implementing a commanding tool dependent only on the eyes. This derives from neural plasticity, an aptitude best seen in children. The delay of computer response to eye saccadic command of a mouse on one sidewill be tolerated during training and on the other will be the objetc of further research, to make the gaze tracker as friendly and quick in response as possible.

\section{References}

BORAH, J. Measurement Techniques for Eye Movement. In: WEBSTER, J.G. (Ed.). Encyclopedia of Medical Devices and Instrumentation. New York: J. Wiley, 2006. p. 323-335.

ENDERLE, J.D. Eye Movements. In: AKAY, M. (Ed.). Wiley Encyclopedia of Biomedical Engineering. New York: J. Wiley, 2006. http://dx.doi.org/10.1002/9780471740360.ebs0471. 
GONZÁLEZ, E.L.; GARCÍA, J.C.; TULLI, J.C. Estudio de factibilidad de un Mouse controlado por señales Electrooculográficas. [S.I.: s.n.], 2005. Trabalho apresentado no XV Congreso Argentino de Bioingenieria, 2005, Paraná, AG.

JIN, S.; LEE, K.; HONG, K. An I mplementation of Multimodal Gaze Direction Recognition System using I mage and EOG. In: INTERNATIONAL CONFERENCE ON DIGITAL CONTENT, MULTIMEDIA TECHNOLOGY AND ITS APPLICATIONS (IDC), 6., 2010, Seoul, KR. Proceedings. [S.I.]: IEEE, 2010. P. 229-235.

NORIS, B.; M.; NADEL, J.; HENTSCH, F. et al. Measuring gaze of children with Autism Spectrum Disorders in naturalistic interactions. In: ANNUAL INTERNATIONAL CONFERENCE OF THE IEEE ENGINEERING IN MEDICINE AND BIOLOGY SOCIETY, 33., 2011, Boston. Conference Proceedings. [S.I.]: IEEE, 2011. P. 53565359.

PEREIRA, J.; SENATORE, A.; TOUYA, A. PANTOJ O Sistema que detecta y transmite la posición de un ojo en tiempo real. 2011. Proyecto de fin de Carrera, Simini F. Tutor, Facultad de Ingeniería, Universidad de la República, 2011, Montevideo, UY.

PEREIRA, J.; SENATORE, A.; TOUYA, A. et al. Determinación de la orientación del ojo mediante procesamiento del electrooculograma. Mar del Plata: [s.n. ], 2001. Trabalho apresentado no XVIII Congreso Argentino de Bioingeniería SABI 2011, Mar del Plata, AG.

SCHIAVONE, G.; GUGLIELMELLI, E.; KELLER, F. et al. A Wearable Ergonomic Gaze-Tracker for Infants. Conference Proceedings of The IEEE Engineering in Medicine and Biology Society, I pswich, MA, p. 1283-1286, 2010.

SIMINI, F. Ingeniería Biomédica Perspectiva desde el Uruguay. Montevideo: Publ. de la Universidad de la República Oriental del Uruguay, 2007. P 141-159.

SIMINI, F.; TOUYA, A.; SENATORE, A. et al. Gaze Tracker by Electrooculography (EOG) on a Head-Band. [S.I.: s.n.], 2011. Trabalho apresentado no 10th Biomedical Engineering Meeting, 2011, Kos, GR.

STIEFELHAGEN, R. Gaze Tracking for Multimodal Human-Computer I nteraction. In: INTERNATIONAL CONFERENCE ON ACOUSTICS, SPEECH, AND SIGNAL PROCESSING, 1997, I pswich, MA. [Proceedings]. I pswiCh, MA: IEEE, 1997. V. 4, p. 2617-2620.

VENKATARAMANAN, S.; PRABHAT, P.; SHUBHODEEP, R. et al. Biomedical Instrumentation based on Electrooculogram (EOG): signal processing and application to a hospital alarm system. In: INTERNATIONAL CONFERENCE ON I NTELLI GENT SENSI NG AND INFORMATION PROCESSI NG, 2005, Guwahati. Proceedings of 2005. Guwahati: Indian Institute of Technology, 2005. P. 535-540. 
YAGI, T.; KUNO, Y.; KOGA, K. et al. Drifting and Blinking Compensation in Electro-oculography (EOG) Eye-gaze Interface. In: INTERNATI ONAL CONFERENCE ON SYSTEMS, MAN AND CYBERNETICS, 2006, Taipei, TW. [Proceedings]. [S.I.]: IEEE, 2006. P. 3222-3226.

Submetido para avaliação 20 mai. 2012.

Aprovado para publicação em 15 jun. 2012.

\section{Franco Simini}

Núcleo de Ingeniería Biomédica de las Facultades de Medicina e Ingeniería, Universidad de la Republica, Montevideo, Uruguay. E-mail: simini@fing.edu.uy

\section{Andres Touya}

Núcleo de Ingeniería Biomédica de las Facultades de Medicina e Ingeniería, Universidad de la Republica, Montevideo, Uruguay. E-mail: adtouya@fing.edu.uy

\section{Agustin Senatore}

Núcleo de Ingeniería Biomédica de las Facultades de Medicina e Ingeniería, Universidad de la Republica, Montevideo, Uruguay. E-mail: agusem@gmail.com

\section{J ose Pereira}

Núcleo de Ingeniería Biomédica de las Facultades de Medicina e Ingeniería, Universidad de la Republica, Montevideo, Uruguay. E-mail: josepereira@fing.edu.uy

\section{Laura De Castellet}

NeuroPaediatric Rehabilitation Professor and Medical Director of Fundación TELETÓN, Montevideo, Uruguay. E-mail: lauracastellet@gmail.com 